\title{
A MODEL OF PROJECT AND ORGANISATIONAL DYNAMICS
}

\author{
Jenny Leonard \\ University of Sydney \\ Email: jenny.leonard@sydney.edu.au
}

\begin{abstract}
The strategic, transformational nature of many information systems projects is now widely understood. Large-scale implementations of systems are known to require significant management of organisational change in order to be successful. Moreover, projects are rarely executed in isolation most organisations have a large programme of projects being implemented at any one time. However, project and value management methodologies provide ad hoc definitions of the relationship between a project and its environment. This limits the ability of an organisation to manage the larger dynamics between projects and organisations, over time, and between projects. The contribution of this paper, therefore, is to use literature on organisational theory to provide a more systematic understanding of this area. The organisational facilitators required to obtain value from a project are categorised, and the processes required to develop those facilitators are defined. This formalisation facilitates generalisation between projects and highlights any time and path dependencies required in developing organisational facilitators. The model therefore has the potential to contribute to the development of IS project management theory within dynamic organisational contexts. Six cases illustrate how this model could be used.
\end{abstract}

\section{INTRODUCTION}

The part that information systems (IS) can play in providing strategic advantages to organisations is well documented Bharadwaj 2000; Perter 2001; Silvius 2007). So, too is the fact that these advantages are not automatic: they require that IS are aligned with the organisation (Henderson and Venkatraman 1993; Luftman 2000; Silvius 2007; Tallon 2007). However, that alignment often needs to be dynamic (Peppard and Breu 2003; Benbya and McKelvey 2006): both information systems and the organisation may be changing rapidly (D'Aveni 1994; Illinitch et al 1996), and, indeed, be operating at the "edge of chaos" Brown and Eisenhardt 1997, 1998). Agility is increasingly seen as the means of survival (Tallon and Pinsonneault 2011). In this context it is unsurprising that IS managers rate "business agility and speed to market" as their second highest concern (Luftman and Ben-Zvi 2011)

However, some strategic IT initiatives take time to deliver value, as they depend on the development of organisational assets which can only be acquired over time (Brynjolfsson 1993; Brynjolfsson and Hitt 1996, 2003; Markus and Tanis 2000; Gregor et al 2006). Indeed, the resource-based view explicitly states that an organisation can sustain competitive advantage if competitors lack the underlying resources to copy it, and cannot acquire those resources quickly (Mata et al 1995; Ross et al 1996; Piccoli and Ives 2005).

IS project managers, then, often find themselves under pressure to deliver results quickly in situations where those results depend on many organisational resources that are not within the project's control. Moreover, projects themselves can make changes to the organisation above and beyond the specific deliverables expected of them. Furthermore, projects almost never occur in isolation - it is typical for large organisations to have large programmes of projects occurring simultaneously, each of which can influence the other (Thiry 2002). 
This paper explores the way in which the dynamics between projects and organisations are currently captured in project management methodologies, asking the question:-

How can the dynamics between projects and organisations be defined and captured in such a way as to enable project managers to effectively deliver value from individual projects, and contribute explicitly to the broader development of the organisation?

The paper first reviews conventional project and value management methodologies, and demonstrates that issues regarding the broader organisation are addressed using risk registers which are by nature ad hoc. This clarifies the contribution of the current paper: namely, to use models found in the strategic information systems literature to model the dynamics between projects and organisations more explicitly. This allows a better capture of the systematic changes that are required if an organisation is to benefit from IS projects. It also allows a more explicit definition of the sources of possible time lags, and the path dependencies. Hence the organisational needs defined and analysed in one project can be used to address the potential organisational needs of future projects.

There have been several different approaches in the literature to looking at the organisational context of information systems projects, all of which can help address the research questions. These include IS-business alignment (Henderson and Venkatraman 1993; Chan and Reich 2007; Tallon and Pinsonneault 2011), Enterprise Systems projects (Davenport 2000; Markus et al 2000; Markus et al 2000a; Willcocks and Sykes 2000), and theories of organisational strategy (Porter 1985, 2001; Mata et al 1995; Wade and Hulland 2004; Zahra et al 2006). More specifically, and based on a review of much of this literature, response-lag drivers have been defined, which conceptualise how the competitive advantage that a "first mover" firm obtains from an IT enabled strategic initiative can be sustained over time. (Piccoli and Ives 2005). Unlike much of the strategy literature, this is based at the project level, and hence informs the project and organisational model developed in this paper.

The current paper uses concepts from the Piccoli and Ives synthesis, together with those from the literature on business value (Melville et al 2004; Tiernan and Peppard 2004) to produce a model of project and organisational dynamics. The model conceptualises the organisational environment as a series of facilitators to a project. Those facilitators can be improved by one or both of two processes, as identified by Piccoli and Ives (2005, pp 751-2), namely organisational learning and asset stock accumulation.

Both processes can be conceptualised in terms of time dependence - they cannot necessarily occur within the time frame of the project - and path dependence - they depend on organisational precursors. Hence, the model can be used to give a better estimate of the time and difficulty involved in making the organisational changes necessary for the project to deliver value to the organisation.

\section{LITERATURE REVIEW}

This review details current methodological approaches to the management of a project within its environment. It then discusses different theoretical approaches to projects in an organisational context, and theories of value from projects, in order to set the scene for the Project and Organisational Dynamics model developed in the following section.

\section{Methodological Approaches to Projects}

Two project management methodologies are widely used, and are available in the public domain, namely PRINCE 2 (Projects IN Controlled environments) (OGC 2005, 2009) published by the UK Government, and PMBOK (The Project Management Body of Knowledge) (PMI 2004, 2008), which is an American Standard. They cover similar material, although PRINCE 2 takes a project lifecycle approach, while PMBOK describes nine function-based knowledge areas (Wideman 2002; PMI 2004 
p9). Both of these methodologies define clear boundaries between the project and the wider environment. Aspects of the environment which are regarded as outside the project include many which, it could be argued, are key to defining the characteristics of the organisation. In the case of PRINCE 2, tools techniques, people, configuration management, mission, strategy, operations, benefits, expectations and programmes are not considered. (OGC 2005 p9). For PMBOK, the environment is described as cultural, social, international, political and physical, and the PMBOK methodology limits itself to stating that the project team needs to understand the effects of the project on these environments (PMI 2004 p14). There are also time boundaries on projects - they are "finite"(OGC 2005 p2) or "temporary" (PMI 2004).

Project management methodologies define and manage externalities to the project using a risk register. While PRINCE 2 defines risk categories as strategic/commercial; economic/financial/market; legal and regulatory; organisational/management/human; political; environmental; and technical/operational/infrastructure (p409), neither methodology gives a systematic way of defining such risks, which can be used across multiple projects.

Moreover, project management methodologies do not offer generic approaches to improving the environment. A typical project risk log might contain such items as "Management Incompetence" or "Infrastructure failure" (OGC 2005 p 410-411). However, it is not made clear how, either during this project, or as part of separate projects, management could be made more competent, or how the infrastructure can be improved.

In addition to, and often used in conjunction with, project management methodologies, there are value management methodologies which focus on the organisation's ability to successfully implement projects. VALIT provides a framework for improving the project environment by improving accountability, clarifying roles and responsibilities, and providing criteria for evaluating projects. However, it does not identify the specific processes that can operate to make improvements to the environment in which the project operates. The Capability Maturity Model (SEI 2007) also provides project guidelines, albeit only for software development projects. It describes three critical organisational dimensions: people, procedures and methods, and tools and equipment, and asserts that processes bring these together. The capability maturity of an organisation depends on the way in which these processes are undertaken. However, while this model names the processes, it does not provide any understanding of how an organisation can reach a higher level of maturity, and in particular of any time dependencies in going from one level to another.

\section{Theories on Information Systems and Organisations}

Project and value management methodologies, and capability maturity models, then, indicate what organisational factors may affect a project, but do not address how they can be ameliorated. They also do not account for the dynamic relationship between a project and its organisational environment. However, several different approaches have been taken to looking at the organisational context of IS, including Enterprise Systems implementation, strategic IS alignment, and theories of strategy. Each of these is now discussed, in terms of the contribution they bring to understanding the dynamics of organisations and projects.

Enterprise System implementation projects represent a subset of projects which require considerable involvement of the organisation for their successful implementation and use. There are several reasons for this: they are predicated on the organisation changing its processes to fit the software (Markus et al 2000a; Kawalek and Wood-Harper 2002), often to the extent that organisational transformation occurs (Willcocks and Sykes 2000); they require integration across large sections of the organisation (Markus et al 2000a) and they evolve (Markus and Tanis 2000). 
It has been advised that Enterprise Systems projects should prepare people by ensuring appropriate organisational structures and roles, as well as preparing the technical system (Davenport 2000). Nine core roles of the CIO and IT function have been identified as important to ensuring that business vision drives the implementation (Willcocks and Sykes 2000). The importance of looking at Enterprise System success appropriately has also been discussed: it has been suggested that four phases should be evaluated: chartering, project, shakedown and onward and upward, rather than being limited to post project evaluation as recommended by project methodologies (Markus and Tanis 2000). Findings regarding Enterprise Systems projects can often be generalised to other IS projects (Willcocks and Sykes 2000). For the purposes of this paper, the Enterprise Systems literature emphasises the need for IS projects to engage with and change the broader organisation, and also to be prepared for time lags before benefits are obtained.

IS-business alignment takes a strategic, organisational level of the relationship between IS and the business. There is a very large body of literature on this subject - see the annotated bibliography and reviews by Chan and Reich (2007, 2007a), and Teo (2009). While alignment does not provide a model of dynamics at the project level, it typically describes a dynamic interplay between IS strategy, business strategy, IT infrastructure and the organisational structure and processes within the business, after the seminal Henderson and Venkatraman model (1993). As such it has the potential to provide a perspective on some of the organisational characteristics that should be considered in any model of project and organisational dynamics. Alignment maturity, for example, has been defined as including quality of communications, competency, governance, partnership, scope of the business, and architecture and skills (Luftman 2000). Alignment between the business plan and the IS plan can also add value to an organisation, and depends on the specific knowledge of both IS and the business among an organisation's executive (Kearns and Lederer 2000, 2003).

Models of strategy may also help in understanding the interaction between projects and organisations. Such models include Porter's work on analysing an organisation's position in the market (Porter 1980, 2001; Porter and Millar 1985), the Resource Based View of the firm (Barney 1995; Mata et al 1995; Wade and Hulland 2004) and dynamic theories of strategy (Eisenhardt and Martin 2000; Zahra et al 2006). Of these three theories, the Resource Based View has particular potential in defining the dynamics between organisations and projects. This View is based on the concept that a firm gets a competitive advantage because its resources are Valuable, Rare, Inimitable and Nonsubstitutable (Barney 1991). Implicit in these definitions are notions of the historical path that organisations have taken in developing those resources, and the uniqueness of combinations of resources (Mata et al 1995).

A more specific indicator of the way in which resources may be affected by projects over time is provided by Piccoli and Ives (2005). They review 117 articles, selected from 648 titles and abstracts and synthesise their findings in a framework. This framework includes response lag drivers: the organisational characteristics which ensure that a strategic initiative by one firm cannot be emulated by others. A subset of the response lag drivers can, with modifications, be conceptualised as the organisational facilitators which ensure that value is obtained from strategic projects. In addition, Piccoli and Ives define two time dependent processes, namely asset stock accumulation and organisational learning. These processes can be used to improve organisational facilitators.

IT business value has been defined as "the organizational performance impacts of information technology" (Melville et al p284). These authors conceptualized value as the way in which IT and other resources, moderated by country and industry characteristics, combine to support business processes, which are the basis of organisational performance. A definition of value at the project level has been provided by (Tiernan and Peppard 2004), in terms of the net benefits from a project after the costs of investment in business and service change, and service running costs, have been considered. Tiernan and Peppard's definition is used in the model developed in this paper. 


\section{The Project and Organisational Dynamics model}

The project and organisational dynamics model is a two part model:-

- Potential POD - The organisational facilitators required for a project to realise its potential value.

- Realised POD - The dynamics between changing organisational facilitators and realised value as the project proceeds.

Each part of the model can be seen as an adjunct to conventional project management models. For example, using PRINCE 2 terms, Potential POD is undertaken once, as part of "project planning". Realised POD is undertaken iteratively during the course of managing "product delivery" (OGC 2005) p12.

\section{Potential POD}

The Potential POD model is shown in Figure 1, above. At the stage of project planning, it is possible to use a set of generic project characteristics to indicate the organisational facilitators that are likely to be required if the project is to succeed in delivering business value. It is also possible to indicate, in generic terms, the nature of business value that is likely to accrue from the project.

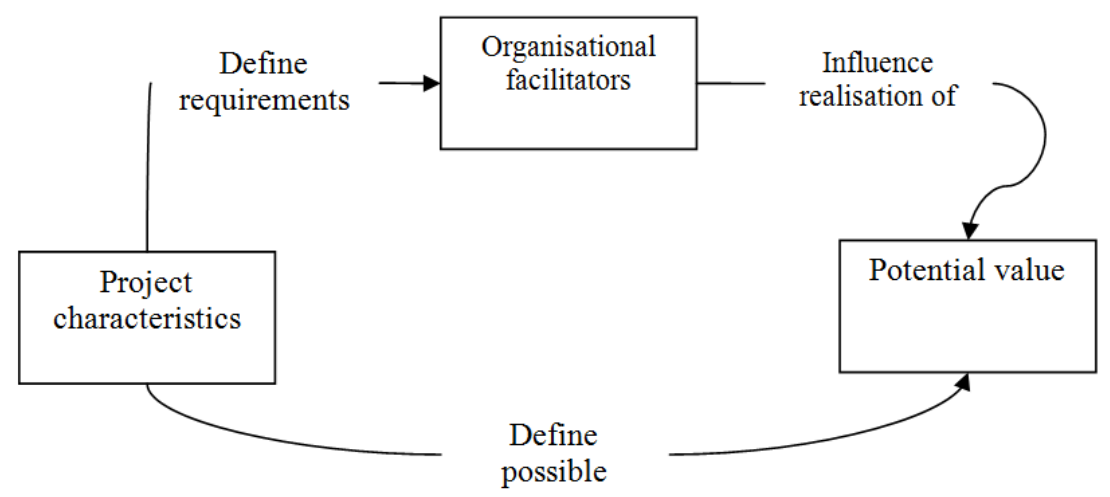

Figure 1: The Potential POD model

The project characteristics are derived from the definition of a "Project Barrier" in Piccoli and Ives 2005 ( $\mathrm{p}$ 761). In the context of Potential POD, project characteristics are those features of the project that can be used to identify the extent to which organisational facilitators are likely to be required.

Two of the project characteristics describe the technology being implemented: namely, its uniqueness and complexity. A unique technology is one which is being implemented in a unique context: either because it has to be custom-built for the organisation, or because the system is highly integrated and/or requires complex integration with other systems. A complex technology is one which, according to Piccoli and Ives, can objectively be said to be complex, no matter which organisation implements it.

The other two project characteristics refer to the implementation itself. One of these is, again, complexity; this time referring to the processes required to ensure the technology is rolled out within 
the organisation. The other is the extent of process change. This can be significant in the case, for example, of an Enterprise System (Markus et al 2000; Kawalek and Wood-Harper 2002).

The Project and Organisational Dynamics model is designed to show how and when an organisation obtains value from a project. Elements from Tiernan and Peppard's paper (2004) on the dynamics of business value been used to define business value as the business benefits, net of the business change investment, service change investment, and service running costs. The extent to which an organisation could potential obtain business value as defined would be informed by project characteristics, as these characteristics will dictate the requirements for organisational facilitators.

Project characteristics will affect the extent to which organisational facilitators are required for its implementation. The Project and Organisational Dynamics model allows a series of organisational facilitators to be modelled together with the organisational learning and/or asset stock accumulation processes required for their improvement. Hence, the model can provide a more in depth understanding of not only what organisational change is required, but also the way in which those changes can be made, and the likely time frames that will be required to make them.

Piccoli and Ives' discussion of organisational learning and asset stock accumulation (pp 751-752) is summarised here.

Organisational learning is defined as "the capacity or processes within an organisation to maintain or improve performance based on experience" (Nevis et al 1995) Organisational learning processes include repetition, experimentation and learning from mistakes (Eisenhardt and Martin 2000). Organisational facilitators which are built by organisational learning include IT management skills, technical skills, top management commitment and corporate culture.

Asset stock accumulation refers to the process of building the unique set of assets to which an organisation has access, and refers specifically to the interdependence between those assets. For example, building an asset such as the IT infrastructure, defined as the base foundation of the IT portfolio, depends on infrastructure already in place. Other, similar assets include the information repository, upon which decision-making is based; and the relationship asset - the rapport built between the IS function and business over time.

Previous experience, often gained on projects, can strengthen each of these organisational facilitators, particularly organisational learning; and most IS projects affect, and are affected by asset stock accumulation.

\section{Realised POD}

The Realised POD part of the model is used during product delivery. In addition to reviewing project tasks, this model facilitates explicit, systematic review of organisational facilitators the way that they change during the project lifetime, and the effect this has on realising elements of the potential value of projects. For example, project characteristics as captured in the Potential POD model might stress the need for a robust information infrastructure: the project might have the potential to improve business intelligence, but only if the robustness of that infrastructure improves: something which may not be in the scope of the project. The Realised POD model, shown in Figure 2 below, provides a way of capturing this dynamic. 


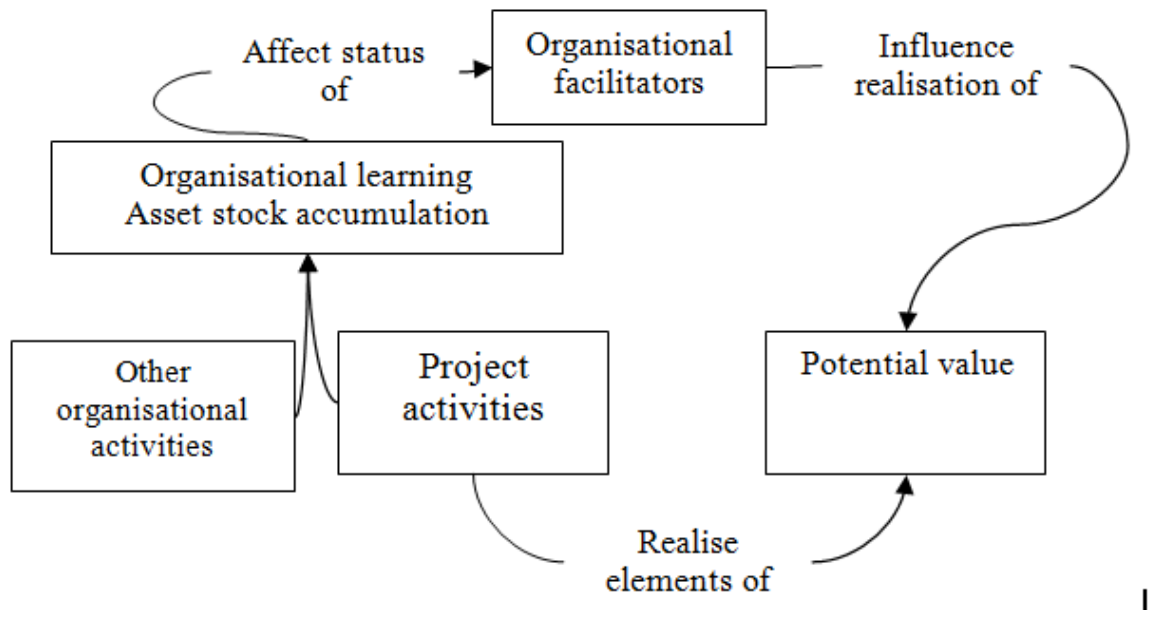

Figure 2 Realised POD

Used in addition to conventional project management methodologies, this two-part POD model allows a dynamic, organisationally focussed way of looking at the relationship between the project and organisation. Instead of seeing organisational issues as risks for a particular project, over that project's lifetime, a longer term view can be taken, reflecting our current understanding of delays in investment in IS (Brynjolfsson 1993; Brynjolfsson and Hitt 1996; Markus and Tanis 2000; Gregor et al 2006). By using generic terms for organisational facilitators, they can be related to different projects, so that the importance of building particular organisational facilitators can be fully understood.

\section{ILLUSTRATING THE PROJECT AND ORGANISATIONAL DYNAMICS MODEL}

To illustrate and evaluate the model, semi-structured interviews were conducted with senior executives in six organisations regarding an IS project for which they had significant responsibility. The executives worked in a range of organisations and industry sectors, and the projects for which they were responsible also varied considerably. The organisations, and the information systems described were as follows. In each case a pseudonym is used for the organisation.

Manuco A manufacturing organisation which had recently implemented an Enterprise System. The Chief Financial Officer and Chief Information Officer held key responsibilities for the project, and both were interviewed.

Uniorg A University that implemented an Enterprise System. The Registrar, who held key responsibilities for one part of the project, was interviewed.

Standardco A company implementing global standards. The Chief Information Officer of the Asia Pacific region was interviewed about a recent extension of a strategic system into a new operational area and geographic region.

Medprac A medical practice that had recently extended its use of an integrated support system. The practice manager responsible for that extension was interviewed.

Pubco A publications company which had recently introduced a mobile merchandising project. The information systems manager, merchandising manager and marketing manager were interviewed. 
Urborg A company that provides urban planning reports. The systems support for this was discussed with the information systems manager.

Interviewees were asked to describe the progress of the project, any positive or negative influences on it, and the benefits and disbenefits it brought to the organisation. They were asked to describe the situation at the end of the project, and any relevant developments between that time and the end of the interview. Interviews were recorded and transcribed, and then analysed using the constructs in the Project and Organisational Dynamics model. The Realised POD analysis was conducted in two iterations: at project completion, and at the date of the interview.

\section{RESULTS}

\section{Manuco}

Manuco, a manufacturing company implemented a new system in the late 1990s to replace legacy systems that were no longer adequate to support its rapidly growing business. The implementation was also undertaken as a solution to $\mathrm{Y} 2 \mathrm{~K}$ problems.

Figure 3 shows the Potential POD model for this project. The Enterprise System implementation involved specific configuration for the organisation and so was unique, was technically complex, involved a complex implementation with significant process change. The potential business benefits expected from the project were coordination of processes across the organisation, and the availability of real time/right time information for decision support. Significant business change investment would potentially be required - although this was not recognised by the original project team, and the service running costs should have been controlled.

To obtain such business benefits, the organisation required technical skills in infrastructure design and process analysis, management skills in project and change management, a good relationship between IT and the business, a top management committed to the implementation, and a corporate culture which understood that an information systems implementation of this type required significant, proactive business input.

However, as Figure 4 shows, the first iteration of the project did not develop many of these facilitators, and as a consequence, business value obtained was limited to the point where there was significant concern regarding the effect on the viability of the organisation: "The IT system cost...was out of control, so if we didn't fix it, the company was going to disappear very quickly" (Chief Financial Officer - CFO).

The IT infrastructure was "old, out of date, not supported, not maintained, run on a computer out the back, no strategy, no nothing" (Chief Information Officer - CIO). IT technical and management skills were poor, and most of the project activities were outsourced in a way which did not allow these skills to develop. The relationship between IT and the business deteriorated during the project. Steering committees were: "a bit like the United Nations. There was lots of discussion, but not a lot of agreement on how to take things forward" (CFO). The project continued along planned timetables without ensuring that the business was involved: "we were rolling out systems before people were ready to accept them" (CFO). Top management commitment was hampered by a lack of understanding of the technology: "The old CEO and the old CFO were not of that generation so they didn't really have any appreciation....they signed off this big project and away it went" (CIO). The lack of understanding of information issues was widespread throughout the business (CFO). 


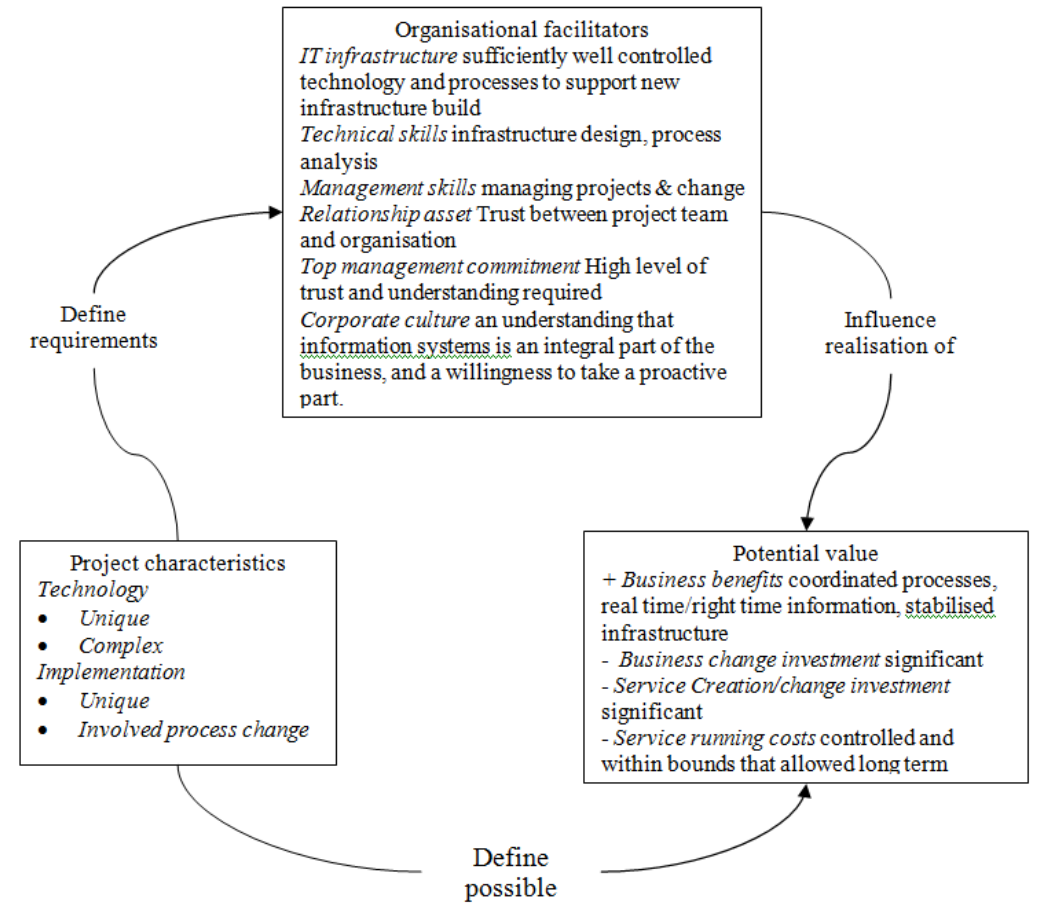

Figure 3: Potential POD at Manuco

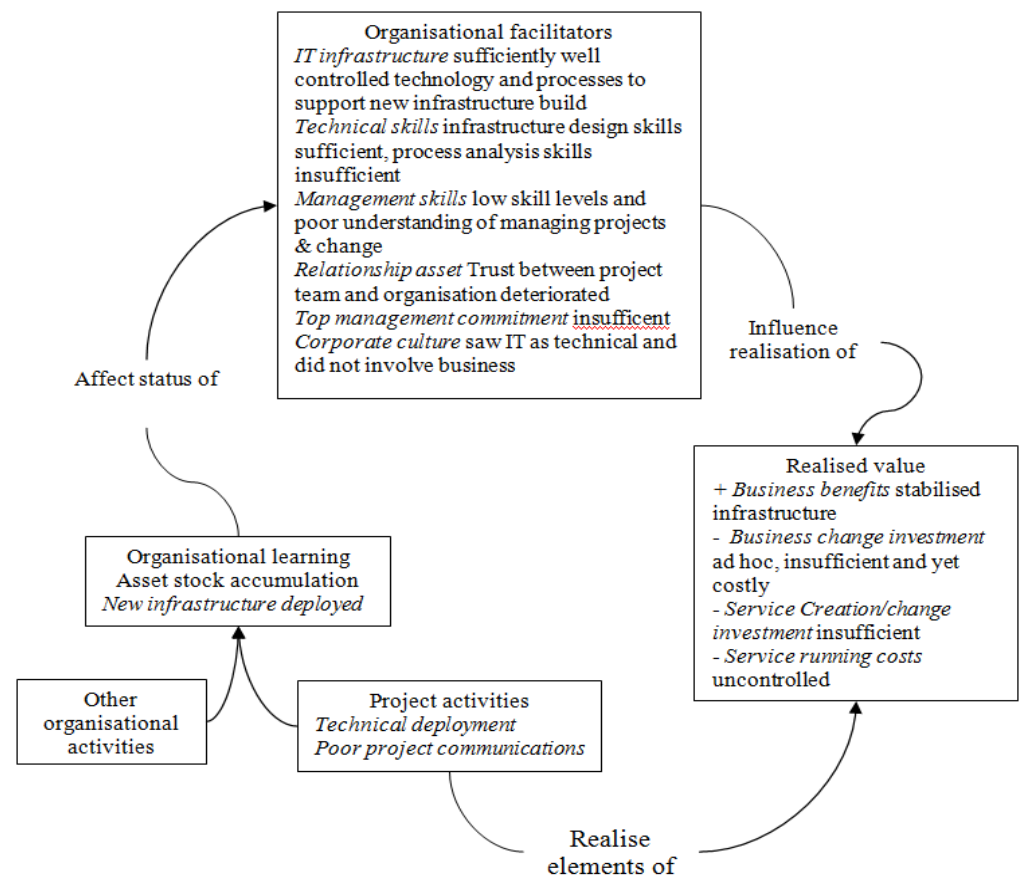

Figure 4: Realised POD at Manuco - iteration 1 
The only business benefits obtained at this stage were regarding infrastructure, an aspect in which the project was: "actually pretty successful: the amount of infrastructure that was implemented in a fairly short period of time for its size" (CIO). However, there were serious cost overruns on both project and running costs: "costs almost doubled [from those expected]... in terms of capital, and really [there was no] fix on operating costs" (CIO). "The IT system costs were a quarter of the market capitalisation cost" (CFO). The cost overruns were contributed mainly to instability in the new infrastructure, and complex system modifications which were required because business processes were neither understood nor changed. These complex modifications did not support processes anyway: "there was a big mismatch between what the system thought people were allowed to do and what in practice they were doing" (CFO).

Since the implementation several significant changes have occurred, some as a result of specific post project activities, and others as a result of other organisational change. Figure 5 illustrates iteration 2 of the Realised POD model which shows the effect of these changes on organisational facilitators and business value.

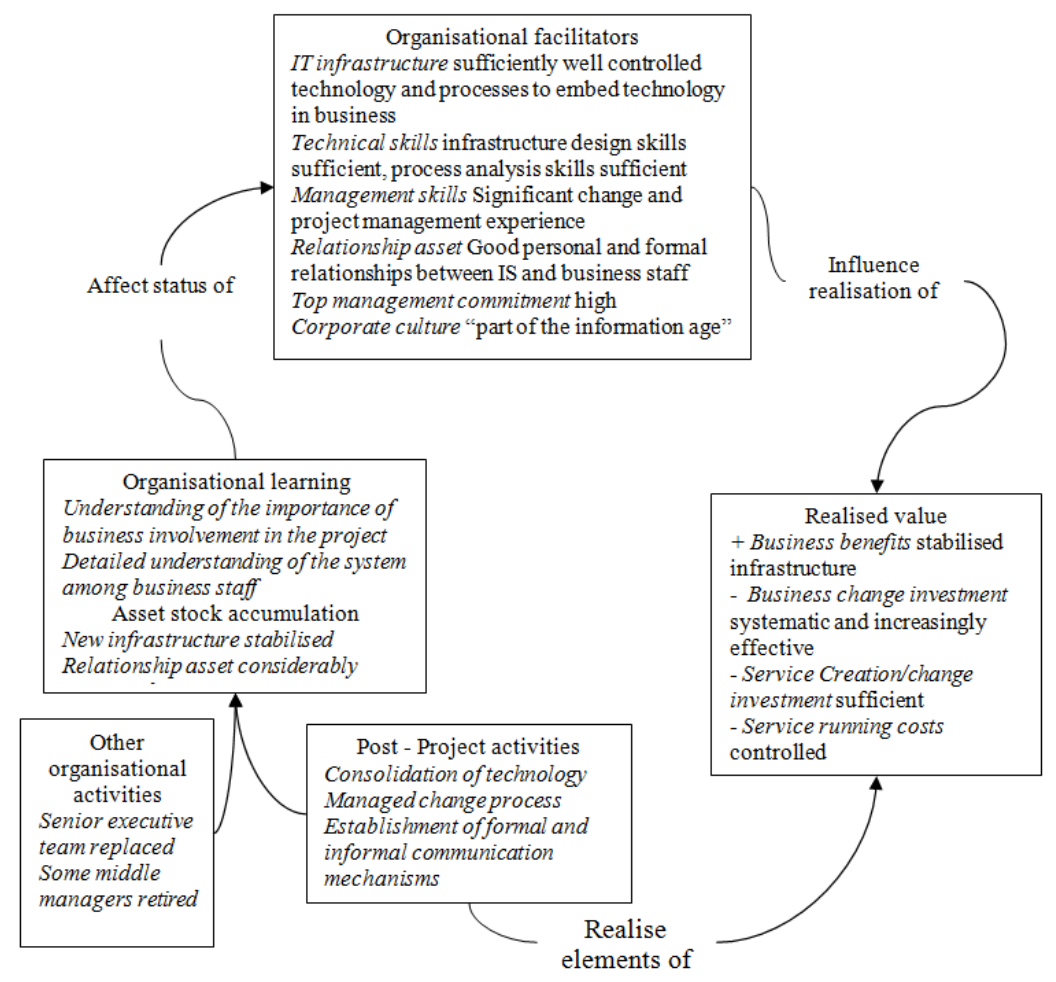

Figure 5: Realised POD at Manuco - iteration 2

A key organisational activity was the replacement of the senior executive: the Chief Financial Officer arrived in 2002, the Chief Information Officer was recruited by the CFO in 2003, and the new Chief Executive Officer arrived in 2004.

Together, they have been responsible for driving significant improvements. The CFO spent almost half his time, when he first arrived, improving the way in which the business interacted with the system. The CIO brought proven project and change management experience to the role, extended 
and consolidated business improvement, and established ongoing relationships with the business. He also improved the technical and managerial skills of his own staff, both through training and recruitment. The new Chief Executive Officer provided significant support. "What did he say to me? You get this thing fixed and you'll be on my Christmas Card list forever" (CIO). The CEO also instituted an executive management team that oversees all IS projects. Relationships among the senior executive were described as "nirvana-ish" (CIO).

The CIO believed that the new executive represented a broader change in culture as older staff are replaced by younger ones who have grown up in the "information age". He contrasted working with the new CEO and CFO who are "in their early forties and have probably never known work without a PC" with the old CEO, whose approach to problems was to "bump the table and say ... 'fix it'. You couldn't even explain to him what was wrong, was it a database, was it an operating system, was it telecommunications? He had no idea".

In terms of value, the infrastructure has been stabilised using an effective, finite investment by the CIO. The business is now obtaining some benefits from integrated processes, albeit using significant resources for business change. The service running costs are now contained.

In the future, the executive team are making plans for further infrastructure improvements, particularly regarding processes, and are further building IS business relationships, in order to obtain better value from their systems investment.

\section{Uniorg}

Uniorg, a large University, also implemented an Enterprise System, consisting of finance, human resources/payroll and student administration. The Potential POD model is hence similar to that for Manuco. In terms of required organisational facilitators, there was one difference: the information repository, in terms of student and course records, was important, and development of this asset was expected during the implementation: "There was a whole lot of detailed information required on an individual student basis, and there was a lot of big picture information on a mass student basis" (Registrar).

The most striking thing about Uniorg compared with Manuco was that many of the required organisational facilitators were already partly in place, and that explicit processes were put in place to develop them further during the project.

The old IT infrastructure was stable, although there was a problem with "feral systems" developed by Faculty members for their own purposes without appropriate reference to organisational integration and standards. As the project proceeded, "we tried very hard to make sure we were meeting needs with the Enterprise System, so that they didn't need to set up what we called feral systems in the satellites". The information repository was developed: "Most important from our point of view was to set business strategy which ensured that the data was collected from and about and for students..." Technical and managerial skills were explicitly developed as part of the project. The Chief Information Officer (CIO) brought in and trained staff. She then put them in the business areas run by the Registrar, thus improving the relationship asset during the project lifetime. In addition, building on the excellent relationships between the two of them, the CIO and Registrar developed the managerial skills of their staff: "between us we managed to get quite a lot of senior staff in both her area and my area trained to be good project managers and ultimately good change managers". Top management commitment was retained. There was an ongoing problem in terms of corporate culture. Academics had unrealistic expectations of the system, both in terms of its flexibility, and in terms of the costs of obtaining information from it. They were "clear what their academic [requirements were], but not how the administrative systems are supposed to actually build into those aspirations [they thought that].. the new system was there to cater to their every whim... they didn't recognise the 
enormous cost of making what I regard as trivial adjustments to their way of doing business. ... They always think that if they put in this wham bam computer system they are going to save money. But what happens in practice is the University becomes more data hungry and wants more things done with the system" (Registrar).

In summary, this system started to deliver benefits within the timeframe of the project. The Registrar regarded the entire project as successful and asserted that the five year project was implemented within budget and on time. Ongoing, minor problems with corporate culture are being managed by organisational learning about system capabilities.

\section{Standardco}

In contrast to the first two organisations, information systems projects in Standardco occur within the context of a "grassroots" approach to systems development, albeit with some "forces to drive within" regarding standards and integration: "We look at global solutions, then global standards, and then at direct development." (CIO).This company, which is more than a hundred years old, provides inspection and verification standards, and is extremely widely dispersed. The interviewee was the CIO for South East Asia, with strategic responsibility for ten countries within that region, and up to ten business lines, from agricultural to automotive, within each country. When seeking to implement new systems he would wait until sufficient organisational facilitators were in place for the project to go ahead.

For example, he described a system for quality audits that had been built from MsAccess systems on 22 sites, with updates to a SQL database. He believed these could be replaced by one of the company's global systems. The technology was not particularly unique or complex, and the implementation was relatively simple. Some process change was required, however. In terms of organisational facilitators required for the project: the infrastructure would be replaced by the project, so was not problematic. Sufficient technical and management skills were available within the company. However, the manager of the business who used the system was not interested. In other words, there was no top management commitment. The CIO waited until a new manager was in place, and was able to build up a sufficient relationship with him to ensure that the system could be successfully implemented.

\section{Medprac}

Medprac, a medical centre had been partially successful in implementing an integrated system. It was being used to write prescriptions and administer appointments, but other system functions, such as stock control systems for medication, patient self check-in and patient notes, were not being used.

The practice manager believed that significant value could be obtained from using the patient notes facility, by improving both the efficiency and effectiveness of patient care: "I thought it was the way forward in terms of helping the patients" (Practice Manager). Computerised notes would mean that doctors could have easy access to them at home, if they needed to visit a patient suddenly, and could have easy access to notes from other doctors - a particular benefit for younger, less confident doctors. Because notes could be coded into type of illness and patient, they could also be used to ensure appropriate preventative care campaigns were implemented: "You could search the database, you could target patients who didn't present themselves but who had problems and make sure they had certain checks. You could generate letters for checkups and flu jabs".

A project to implement the computerisation of patient notes did not involve complex or unique technology, nor was the implementation process itself complex. However, process change was required - doctors had to change their mode of operating from using handwritten notes. As part of the project, a specific organisational facilitator was put in place: an information repository of patient 
histories was developed, by employing a nurse to summarise and data enter patient records. Once this repository was in place, it was possible to improve another organisational facilitator: corporate culture. Like the CIO of Manuco, the practice manager found that the "information age" of some staff could be a problem. Younger doctors had little difficulty using the system, in fact some of them contributed directly to the project by coding the notes. However: "the older ones were less keen; well, they're used to going scribble scribble scribble and suddenly... they're being asked to identify what to code it against and then to have to type, heavens above, very slowly, with two fingers". The organisational learning process here included peer pressure, to the point where "even the most old fashioned doctor" was typing up his notes.

\section{Pubco}

Pubco, a publications company, was able to implement strategic projects by drawing on a legacy of organisational facilitators, due to a previous visionary manager. This manager had made improvements to the relationship asset: "broke down existing walls straightaway, and gave us clear direction...she was collaborative... and appreciated technology" (IS manager). She also improved IT management skills, both by her direct influence on the IS manager, and by sponsoring his education. This led, further, to his improving the management skills of his own staff. As a result her successor has "seen the advantage that...investing in technology has given [the organisation]" (IS manager), and thus top management commitment, and a corporate culture of information awareness has been sustained.

An example system implementation within this environment was a mobile merchandising project, which involved providing the merchandisers who stock newsagents with mobile technology, to enable them to check compliance more effectively (in other words that newsagents were displaying magazines and advertising material as agreed), and in particular, providing the organisation with more accurate, timely data on product availability and demand. The technology was unique, and there was considerable process change required, but the complexity of both the technology and the implementation were low. Both the merchandising manager and the IS manager saw the main organisational facilitator required as corporate culture. The merchandisers were part time casuals aged anywhere between 24 and 60, some of whom had "not used a mobile phone before" (merchandising manager). Considerable emphasis was placed, therefore, on organisational learning: ensuring the merchandisers were fully informed of the benefits, and given plenty of training. As a result they did not lose one staff member, and the project was regarded as a success.

\section{Planorg}

Planorg provides planning, valuations and economic and social analyses. Its main output, therefore, is reports, and this provides it with two specific information systems support needs. Firstly, it needs to produce those reports efficiently and effectively, and in a consistent style. Secondly, it needs to keep records of reports and business correspondence for a fairly long time. Currently, these needs are supported by a combination of Word, Excel, and Outlook. A series of templates are used in Word and Excel, to support corporate style. Excel models are used to help with the analysis of these reports. Backups of business correspondence via Outlook are made on a regular basis, although the length of time for which these should be kept is currently under review. The organisation is growing very quickly - from 44 people eight years ago, to 320 now. As a result, the company is in the early stages of evaluating document management systems, and is aware that it needs to put some organisational facilitators in place in order to do so. Corporate culture needs to be changed - people currently tend to keep their "own" information and hence do not see the advantage of organisation wide systems. Organisational learning is making a positive impact in two ways. Firstly, as the company grows, people are having to delegate responsibility: senior people have "started letting juniors in on some of their secrets". Secondly, people no longer have room to store their own information, and are thus 
archiving it, and contributing to the information repository. Once they learn that information comes back from archive on request, they become less resistant to information sharing. The information systems manager believes that the document management system implementation will occur once sufficient change has occurred to corporate culture.

\section{DISCUSSION}

Tables 1 to 3 summarise the findings for all six cases.

\begin{tabular}{|l|l|l|l|l|l|l|}
\hline $\begin{array}{l}\text { Key: } \\
\sqrt{ } \text { Project characteristic required }\end{array}$ & $\begin{array}{l}\text { Man } \\
\text { uco }\end{array}$ & $\begin{array}{l}\text { Uni } \\
\text { org }\end{array}$ & $\begin{array}{l}\text { Stan } \\
\text { dard } \\
\text { co }\end{array}$ & $\begin{array}{l}\text { Med } \\
\text { prac }\end{array}$ & $\begin{array}{l}\text { Pub } \\
\text { co }\end{array}$ & $\begin{array}{l}\text { Plan } \\
\text { org }\end{array}$ \\
\hline Unique technology & $\sqrt{ }$ & $\sqrt{ }$ & & & & \\
\hline Complex technology & $\sqrt{ }$ & $\sqrt{ }$ & & & & \\
\hline Complex implementation process & $\sqrt{ }$ & $\sqrt{ }$ & & & & \\
\hline $\begin{array}{l}\text { Process change required as part of } \\
\text { implementation }\end{array}$ & $\sqrt{ }$ & $\sqrt{ }$ & $\sqrt{ }$ & $\sqrt{ }$ & $\sqrt{ }$ & \\
\hline
\end{tabular}

Table 1: Project characteristics

\begin{tabular}{|c|c|c|c|c|c|c|c|c|c|c|c|c|}
\hline $\begin{array}{l}\text { Key: } \\
\text { - Organisational facilitator } \\
\text { deteriorated } \\
\text { +Organisational facilitator improved }\end{array}$ & \multicolumn{2}{|c|}{$\begin{array}{l}\text { Man- } \\
\text { uco }\end{array}$} & \multicolumn{2}{|c|}{$\begin{array}{l}\text { Uni } \\
\text { org }\end{array}$} & \multicolumn{2}{|c|}{$\begin{array}{l}\text { Stan } \\
\text { dard } \\
\text { co }\end{array}$} & \multicolumn{2}{|c|}{$\begin{array}{l}\text { Med } \\
\text { prac }\end{array}$} & \multicolumn{2}{|c|}{ Pub co } & \multicolumn{2}{|c|}{$\begin{array}{l}\text { Plan } \\
\text { org }\end{array}$} \\
\hline Iteration & 1 & 2 & 1 & 2 & 1 & 2 & 1 & 2 & 1 & 2 & 1 & 2 \\
\hline \multicolumn{13}{|l|}{ Dependent on organisational learning } \\
\hline Technical skills & & + & + & & & & & & & & & \\
\hline Management skills & & + & + & & & & & & & + & & \\
\hline Top management commitment & & + & + & & & & & & & & & \\
\hline $\begin{array}{l}\text { Corporate culture: information } \\
\text { awareness/ information age }\end{array}$ & & + & & & & & + & & & & & + \\
\hline \multicolumn{13}{|l|}{$\begin{array}{l}\text { Dependent on asset stock } \\
\text { accumulation }\end{array}$} \\
\hline IT infrastructure & + & & + & & + & & & & & & & \\
\hline Information repository & & & + & + & & & + & & & & & \\
\hline Relationship asset & - & + & + & + & & & & & & + & & \\
\hline
\end{tabular}

Table 2: Changes to organisational facilitators 


\begin{tabular}{|l|l|l|l|l|l|l|l|l|l|l|l|l|l|l|}
\hline $\begin{array}{l}\text { Key: } \\
\text { + Better than expected } \\
\text { - Worse than expected } \\
\text { = As expected }\end{array}$ & $\begin{array}{l}\text { Man } \\
\text { uco }\end{array}$ & $\begin{array}{l}\text { Uni } \\
\text { org }\end{array}$ & $\begin{array}{l}\text { Stan } \\
\text { dard } \\
\text { co }\end{array}$ & $\begin{array}{l}\text { Med } \\
\text { prac }\end{array}$ & \multicolumn{2}{|l|}{ Pub co } & \multicolumn{2}{l|}{$\begin{array}{l}\text { Plan } \\
\text { org }\end{array}$} \\
\hline Iteration & 1 & 2 & 1 & 2 & 1 & 2 & 1 & 2 & 1 & 2 & 1 & 2 \\
\hline Business benefits & - & $=$ & $=$ & & $=$ & & $=$ & & & $=$ & & $=$ \\
\hline Business change investment & - & - & $=$ & & & & & & & & & \\
\hline Service creation/ change investment & - & - & $=$ & $=$ & & & & & & & & \\
\hline Service running costs & - & $=$ & $=$ & & & & & & & & & \\
\hline Net value & - & - & $=$ & + & $=$ & & $=$ & & & $=$ & & $=$ \\
\hline
\end{tabular}

Table 3: Realised Value

In each case, the model was able to describe the interaction of the project with its organisational environment. Defining project characteristics helped to indicate the necessity for particular organisational facilitators. Manuco and Uniorg implemented complex, unique systems, requiring complex implementation processes and considerable process change. For both these organisations, a series of similar organisational facilitators were required. The model allowed the problems with the implementation in Manuco to be described, not in static terms, but in ways which would facilitate an understanding of iterative organisational change which could lead to the realisation of business value. The success of Uniorg's implementation could be formally described in terms of organisational learning processes that improved organisational facilitators within the project lifetime.

For some simpler technology solutions, business value can only be obtained if the project goes ahead after certain organisational facilitators are in place. This was the case in Standardco, and Planorg is still waiting for an opportunity. The value of the Project and Organisational Dynamics model in such situations is that it formalises the assessment of whether the "time is right" for an implementation.

The model also has the potential to formalise path dependence in the development of organisational facilitators. For example, both Medprac and Planorg developed information repositories. As those information repositories developed, so opportunities for organisational learning occurred.

The potential of the model to indicate how organisational facilitators developed in previous projects can influence their successors was indicated, although not formalised, in Pubco. Here, a legacy of organisational facilitators developed by a previous senior executive is being utilised and further developed in current projects.

The illustrative cases, then, have indicated that the Project and Organisational Dynamics Model can be used to formalise and explain the organisational facilitators required to obtain value from a project, and the processes required to improve those facilitators.

\section{CONCLUSION}

In this paper, a model has been developed which draws on an extensive literature review on information systems and organisational development. Initial tests of the model indicate its potential to improve our understanding of the dynamic interplay between a project and its environment, across a number of different types of IS projects, in a number of different industries.

This model has implications for practitioners. Its use as part of project planning methodologies within an organisation would, over time, allow project outcomes to be more systematically understood in 
terms of their contribution to the unique resource bundle of the organisation, and would also allow a better understanding of the precursors to the success of each project being undertaken.

As far as research is concerned, the model provides stronger links between project management theory and organisational theory. Further research work in this area could include longitudinal studies, to test the model's robustness.

\section{REFERENCES}

Barney, J.B. (1991). "Firm resources and sustained competitive advantage" Journal of Management 17(1): 99-120

Barney, J.B. (1995) "Looking inside for competitive advantage" Academy of Management Executive 9(4): 49-61

Benbya, H. an B. McKelvey (2006). "Using coevolutionary and complexity theories to improve IS alignment: a multi-level approach" Journal of Information Technology 21: 284-298

Bharadwaj, A. (2000) “A Resource-Based Perspective on Information Technology and Firm Performance: An Empirical Investigation” MIS Quarterly 24 (1) 169 - 196

Brown, S.L. and K.M. Eisenhardt (1997). "The Art of Continuous Change: Linking Complexity Theory and Time-paced Evolution in Relentlessly Shifting Organizations" Administrative Science Quarterly 42: 1 - 34

Brown, S.L. and K.M. Eisenhardt (1998) "Competing on the Edge: Strategy as Structured Chaos" Harvard Business School Press, Boston, Massachussets

Brynjolfsson, E. "The productivity paradox of information technology: Review and Assessment" Communications of the ACM 36 (12) 67 - 77.

Brynjolfsson, E. and L. Hitt (1996) "Paradox Lost? Firm-level Evidence on the Returns to Information Systems Spending” Management Science 42(4): 541-558

Brynjolfsson, E. and L. Hitt (2003) "Computing Productivity - Firm Level Evidence" MIT Sloan Working Paper 4210-01

Chan, Y.E. and B. H. Reich (2007). "IT alignment" an annotated bibliography" Journal of Information Technology 22 (4): 316 - 396.

Chan, Y.E. and B.H. Reich (2007a) "IT alignment: what have we learned?" Journal of Information Technology 22 (4): $316-396$

D’Aveni, R.A. (1994) “Hypercompetition: “Managing the Dynamics of Strategic Maneuvring” Simon and Schuster.

Eisenhardt, K.M. and J.A. Martin (2000) "Dynamic Capabilities: What are they?" Strategic Management Journal 2000 (21): 1105 - 1121

Gregor, S., M. Martin et al (2006) "The transformational dimension in the realization of business value from information technology" Journal of Strategic Information Systems 15: 249 - 270

Henderson, J. and N. Venkatraman (1993): Strategic Alignment: Leveraging Information Technology for transforming organisations” IBM Systems Journal 32, 1 (1993); 38, 2 \&3 (1998)

Illinitch, A.Y, R.A D’Aveni et al (1996) 'New Organizational Forms and Strategies for Managing in Hypercompetitive Environments" Organization Science 7(3)

Kawalek, P. and T. Wood-Harper (2002) "The Finding of Thorns: User Participation In Enterprise Systems Implementation” The Database for Advances in Information Systems 33(1): 13-22

Kearns, G.S. and A.L. Lederer (2000). "The effect of strategic alignment on the use of IS-based resources for competitive advantage” Journal of Strategic Information SYstems 9: 265-293 
Kearns, G.S. and A.L. Lederer (2003) "A resource-based view of strategic IT alignment: How knowledge sharing creates competitive advantage" Decision Sciences 34(1): 1 - 29

Luftman, J. (2000) "Assessing Business-IT Alignment Maturity" Communications of the Associations for Information Systems 4

Luftman, J. and T Ben-Zvi (2011) "Key Issues for IT Executives 2011: Cautious Optimism in Uncertain Economic Times" MIS Quarterly Executive 10(4).

Markus, M. L., S Axline et al (2000) "Learning from adopters' experiences with ERP": problems encountered and success achieved" Journal of Information Technology 15: 245-265

Markus, M.L. and C. Tanis (2000a). "The enterprise experience - from adoption to success" in Framing the Domains of IT Research: Glimpsing the Future Through the Past" ed R.W. Zmud, Pinnaflex Educational Resources, Cincinatti, $\mathrm{OH}$.

Markus, M.L. and C Tanis (2000a) "Multisite ERP implementations" Communications of the ACM $43(4)$

Mata, F. J. W Fuerst et al (1995) "Information Technology and Sustained Competitive Advantage: A Resource-Based Analysis" MIS Quarterly: 487 - 505

Melville, N., K. Kraemer et al (2004): Review: Information Technology and Organizational Performance: An Integrative Model of IT Business Value” MIS Quarterly 28 (2): 283 - 322

Nevis, E.C., A.J. DiBella et al (1995) "Understanding Organizations as Learning Systems" Sloan Management Review 36(2) 73-85

OGC (Office of Government Commerce) (2005, 2009) Managing Successful Projects with Prince 2: The Stationery Office, UK.

Peppard, J. and K. Breu (2003) "Beyond Alignment: A coevolutionary view of the information systems strategy process" Twenty-fourth International Conference on Information Systems.

Piccoli, G. and Ives, B. (2005) "Review: IT - dependent strategic initiatives and sustained competitive advantage: A review and synthesis of the literature" MIS Quarterly 29 (4) 747-776

PMI (2004, 2008): “Guide to the Project Management Body of Knowledge”, Project Management Institute

Porter, M.E. (1980) “Competitive Advantage” New York, Free Press

Porter, M.E. (1985, 1998) Competitive Advantage: Creating and Sustaining Superior Performance (with 1998 introduction) New York, Free Press

Porter, M.E. (2001) "Strategy and the Internet" Harvard Business Review 62-78

Porter, M.E. and V.E. Millar (1985) "How Information Gives you a Competitive Advantage” Harvard Business Review 63(4) 149 - 160

Ross, J.W., C.M. Beath et al (1996) "Develop long-term competitiveness through IT assets" Sloan Management Review

SEI (Software Engineering Institute) (2007) CMMI for Acquisition, Version 1.2" http://www.sei.cmu.edu/library/abstracts/reports/07tr017.cfm accessed $5^{\text {th }}$ April 2012

Silvius, G.A.J. (2007) "Business and IT alignment in theory and practice" Proceedings of the $40^{\text {th }}$ Hawaii International Conference on Systems Sciences Hawaii

Tallon, P.P. (2007) “A Process Oriented Perspective on the Alignment of Information Technology and Business Strategy" Journal of Management Information Systems 24 (3): 227-268

Tallon, P.P. and A. Pinsonneault (2011): "Competing perspectives on the link between strategic information technology alignment and organizational agility: Insights from a mediation model" MIS Quarterly 35(2) 463 - 486 
Teo, T.S.H. (2009)“Aligning business and information systems: review and further research directions". In Advances in Management Information Systems, ed W.R. King, M.E. Sharpe, Armonk, New York

Thiry, M. (2002) "Combining value and project management into an effective programme management model” International Journal of Project Management 221-227

Tiernan, C. and J. Peppard (2004): "Information Technology: Of Value or Vulture" European Management Journal 22(6) 609 - 623

Wade, M. and J. Hulland (2004) "Review: The Resource Based View of Information Systems Research: Review, Extension and Suggestions for Future Research" MIS Quarterly 28(1) 107 $-142$

Wideman, R.M. (2002) “Comparing PRINCE2 with PMBOK” Retrieved $5^{\text {th }}$ April 2012 from www.maxwideman.com/papers/comparing/comparing.pdf

Willcocks, L. and R. Sykes (2000): "The role of the CIO and IT function in ERP" Communciations of the ACM 43(4) 32-38

Zahra, S.A., H.J. Sapienza et al (2006) "Enterpreneurship and Dynamic Capabilities: A Review, Model and Research Agenda" Journal of Management Studies 43(4): 917 - 955 